\title{
The effectiveness of vision screening by school nurses in secondary school
}

\author{
Gerry Jewell, Barnaby Reeves, Kate Saffin, Barbara Crofts
}

\begin{abstract}
Vision screening of 13 and 15 year old children by school nurses in Oxfordshire has declined in recent years due to the pressure of other commitments. A study was carried out to evaluate the likely consequences of failing to provide vision screening for secondary schoolchildren, in order to make a decision about the future of the service. Parents were also asked to complete a questionnaire about their children's past eye histories. Eight schools that had had no vision screening for at least three years participated in the study. Overall, $3 \cdot 8 \%$ of children between 13 and 15 years old had a visual acuity of worse than $6 / 12$ in one or both eyes, that is they failed vision screening; there was no evidence that this percentage increased significantly across this age range. Less than $1 \%$ of children were prescribed and wore spectacles as a consequence of failing vision screening and no new cases of eye pathology were detected. Questionnaire responses suggested that about $50 \%$ of children who did not wear spectacles had had an eye examination in the previous two years. The results indicate that vision screening is not the best way to meet the eye/vision needs of secondary schoolchildren. Strategies for targeting the school nursing resource more appropriately are being considered.

(Arch Dis Child 1994; 70: 14-18)
\end{abstract}

Oxford Eye Hospital, Radcliffe Infirmary, Oxford

Barnaby Reeves

Barbara Crofts

Community Nursing

Unit, East Oxford

Health Centre, Cowley

Road, Oxford

OX4 1XD

Gerry Jewell

Kate Saffin

Correspondence to: Mrs Saffin.

Accepted 19 September 1993

Vision screening in schools is the responsibility of school nurses. It represents a continuation of primary vision care for children, provided during the preschool years by health visitors and orthoptists. Screening usually involves testing a child's monocular visual acuities, with spectacles if available.

Vision assessment in schools was initiated in 1908 to provide national data on the prevalence of disability and disease. ${ }^{1}$ It was only later, probably in the $1950 \mathrm{~s}$, that treatment was offered to children who were identified.

Table 1 Details of school vision screening of 13 and 15 year olds in Oxfordshire, 1984-92

\begin{tabular}{lcll}
\hline Year & $\begin{array}{l}\text { No of children } \\
\text { screened }\end{array}$ & $\begin{array}{l}\text { No (\%) children } \\
\text { referred }\end{array}$ & $\begin{array}{l}\text { No (\%) children with known } \\
\text { ocular/vision problem }\end{array}$ \\
\hline 1984 (Jan-Dec) & 12123 & $740(6 \cdot 1)$ & $1321(10 \cdot 9)$ \\
1985 (Jan-Dec) & 11715 & $529(4 \cdot 5)$ & $1314(11 \cdot 2)$ \\
1986 (Jan-Dec) & 10101 & $395(3 \cdot 9)$ & $1356(13 \cdot 4)$ \\
$1987 / 8$ (Apr-Mar) & 9024 & $331(3 \cdot 7)$ & $1199(13 \cdot 3)$ \\
1988/9 (Apr-Mar) & 9289 & $388(4 \cdot 2)$ & $1217(13 \cdot 1)$ \\
1989/90 (Apr-Mar) & 7207 & $264(3 \cdot 7)$ & $1167(16 \cdot 2)$ \\
1990/1 (Apr-Mar) & 4638 & $217(4 \cdot 7)$ & $788(17 \cdot 0)$ \\
1991/2 (Apr-Mar) & 3243 & $198(6 \cdot 1)$ & $511(15 \cdot 8)$ \\
\hline
\end{tabular}

Stewart-Brown and Haslum' stated that 'The point at which the original "national health survey" became a "national screen" ... certainly predated the scientific consideration of screening programmes in the 1960s that produced well defined criteria for screening. ${ }^{2}$, They concluded that vision testing has never been critically appraised in the way that would be necessary for a new screening programme today.

Despite a lack of information about the costs and benefits of school vision screening and the frequency with which it should be carried out, it has been widely stated that it is important to screen children's vision regularly during the school years. ${ }^{3-5}$ For example, it has been recommended that children should be screened at school entry and at three yearly intervals thereafter, ${ }^{5}$ although no empirical evidence was offered to support this recommendation. In Oxfordshire, vision screening is carried out at $5,10,13$, and 15 years of age but, because of increasing demand for other community paediatric services, the number of 13 and 15 year olds being screened has dropped from about 12123 in 1984 to only 3243 in $1991 / 2$ (table 1 ).

Children of secondary school age are unlikely to have serious undetected vision pathology, although the onset of myopia among teenagers is common ${ }^{6}$ and may have educational implications as children prepare for GCSE examinations. The possibility of educational disadvantage appears to have been the primary reason for school vision screening, particularly for older children. Unfortunately, it has been difficult to evaluate how many children with poor visual acuity may have remained undetected because of the decline in vision screening in secondary schools. Although an audit system exists, the child health service is informed of outcomes for only about two thirds of children who are referred to optometrists, with this proportion decreasing rapidly with age.

In order to make a rational decision about the future of vision screening in secondary schools, it was decided to evaluate secondary school vision screening. The study aimed (a) to determine whether the number of undiagnosed defects detected justified providing the service and (b) to provide information about the best age for vision screening in secondary schools, balancing the higher yield expected at older ages ${ }^{6}$ against the potential disadvantage of a delay in detection for some children. Parents were also asked to complete a questionnaire about their children's past eye histories. 


\section{Method}

DESIGN OF STUDY

A cross sectional design was used. This design assumes that increases in the percentage of 14 and 15 year old children with vision problems compared with 13 year olds reflects the incidence of undetected vision problems in the older age groups. The referral rate in 13 and 15 year old children still being screened was estimated to be about 5\% (table 1). Without vision screening, it was considered that about half the 13 year olds who would have been referred would refer themselves to an optometrist, with the other half carrying over to the next year. Therefore, a target sample size of 500 children in each age group was set, allowing a cumulative increase in referral rate of about $4 \%$ over the age range studied to be detected $(p<0.05$, one tailed) with a power of $0 \cdot 80$.

\section{SUBJECTS}

Nine schools in Oxfordshire, which had had no school nurse vision screening for children over 10 years of age for at least three years, were asked to take part in the study; one refused, one was used to pilot data collection, and data were collected from the remaining seven. Children were recruited by class year (years 8 , 9 , and 10 corresponding approximately to 13 , 14 , and 15 year olds). Because of the spread of ages within a class, the ages of a few children did not match the class year.

\section{PROCEDURE}

Teachers gave every child in the class years studied a consent form to take home. The form was also used to ask parents about their child's past eye/vision history. Schools were asked to set aside a quiet area for testing. A nurse (GJ) used a non-illuminated domiciliary Snellen chart viewed at 6 metres to record children's visual acuities, with spectacles if available. Children who failed to meet the visual acuity criterion were given a referral letter to take to an optometrist, except for those who had attended an eye test in the preceding six months.

CRITERION FOR FAILING VISION SCREENING In Oxfordshire, nurses are recommended to refer children 'at 6/12', although they are

Table 2 Details of the children approached and tested in each year by the school nurse, with the visual acuity data for those tested; data are number (\%)

\begin{tabular}{llcr}
\hline & Year 8 & Year 9 & Year 10 \\
\hline Children approached & 546 & 625 & 625 \\
Consent forms returned & $403(74)$ & $435(70)$ & $354(57)$ \\
Consent obtained & $371(92)$ & $377(87)$ & $321(91)$ \\
Sex: & & & \\
$\quad$ Boys & $176(47)$ & $175(46)$ & $151(47)$ \\
$\quad$ Girls & $195(53)$ & $202(54)$ & $170(53)$ \\
Spectacles: & $48(13)$ & $50(13)$ & $53(17)$ \\
$\quad$ Wearing & $323(87)$ & $327(87)$ & $268(83)$ \\
$\quad$ Not wearing & $361(97)$ & $363(96)$ & $304(95)$ \\
Visual acuity: & $10(3)$ & $14(4)$ & $17(5)$ \\
$\quad$ Right and left 6/12 or better & 1 & $5(1)$ & $6(2)$ \\
$\quad$ Right and/or left worse than 6/12 & $32(9)$ & $28(7)$ & $29(9)$ \\
$\quad$ Right and left worse than 6/12 & & & \\
Right and/or left worse than 6/9 & &
\end{tabular}

believed to use their judgment when deciding whether or not to refer children who have borderline visual acuities. In the study a strict criterion was implemented ${ }^{\star}$; any child who had a visual acuity of worse than $6 / 12$ in either eye was deemed to have failed the screening test. This Snellen criterion is considered equivalent to the 'number plate test' and has also been used to define visual impairment. ${ }^{8}$

\section{CONSENT FORM/QUESTIONNAIRE}

Parents who withheld consent did not complete the questionnaire but were still asked to return the form to the class teacher. Parents who gave consent were asked whether the child had spectacles or not. For children who had spectacles, subsequent questions were asked about wearing time, the age when spectacles were first prescribed, how the vision problem was first detected, and how recently the child had had an eye test. For those who did not have spectacles, parents were asked when their child had last had his/her vision checked, whether the child had ever failed a vision check and, if so, whether spectacles had been prescribed.

\section{Results}

A total of 1796 children were approached, but less than $60 \%(371,377$, and 321 in years 8,9 , and 10 respectively, table 2 ) were tested. The main reason for failing to test such a high proportion of children was that many consent forms were not returned. Consent was given for $90 \%$ of children for whom forms were returned.

No details are available for the children who did not take part, but we believe that the high non-response rate does not undermine the representativeness of the study. Forms given to children to take home often 'go missing', and the highest and lowest non-response rates were observed in adjacent schools that have similar catchment areas; the nurse observed that the response rate appeared to depend primarily on the cooperation of teachers in persuading children to return the forms. The proportion of girls in the study sample (53\%) was higher than expected, ${ }^{9}$ suggesting that boys may have been slightly under represented. Overall, 14\% of children wore spectacles when being tested (table 2), which agrees quite closely with the percentage of screened children described as 'already having treatment' in previous years (table 1).

Forty one $(3 \cdot 8 \%)$ of children were found to have visual acuity worse than $6 / 12$ in one or both eyes, ${ }^{\star}$ with the percentage increasing with age $(2 \cdot 7 \%$ in year $8,3 \cdot 7 \%$ in year $9,5.3 \%$ in year 10 ); the visual acuities of individual children are shown in table 3 . If a 'worse than $6 / 9$ criterion' had been used, $8 \%$

*There was one exception, namely a girl with $6 / 12$ visual acuity in both eyes who complained of poor vision. She was subsequently referred to her general practitioner by her optometrist. 
Table 3 Outcome of vision screening for children with visual acuity of worse than $6 / 12$ in one or both eyes. Right (RVA) and left (LVA) visual acuities are also shown for individual children in each class year

\begin{tabular}{|c|c|c|c|c|c|c|c|}
\hline & \multicolumn{2}{|c|}{ Year 8} & \multicolumn{2}{|c|}{ Year 9} & \multicolumn{2}{|c|}{ Year 10} & \multirow[b]{2}{*}{ Total } \\
\hline & $R V A$ & $L V A$ & $R V A$ & $L V A$ & $R V A$ & $L V A$ & \\
\hline \multicolumn{8}{|l|}{ Children not known to have a vision problem: } \\
\hline Referred, wearing prescription & $6 / 6$ & $6 / 18$ & $6 / 18$ & $6 / 18$ & $\begin{array}{l}6 / 18 \\
6 / 18 \\
6 / 18 \\
6 / 18 \\
6 / 12\end{array}$ & $\begin{array}{l}6 / 18 \\
6 / 18 \\
6 / 12 \\
6 / 9 \\
6 / 18\end{array}$ & 7 \\
\hline Referred, not wearing prescription & & & $6 / 18$ & $6 / 9$ & & & 1 \\
\hline Referred, not prescribed & $\begin{array}{l}6 / 5 \\
6 / 5 \\
6 / 12\end{array}$ & $\begin{array}{l}6 / 18 \\
6 / 18 \\
6 / 18\end{array}$ & & & & & 3 \\
\hline Referred to eye hospital & $6 / 24$ & $6 / 24$ & $6 / 12$ & $6 / 12$ & & & 2 \\
\hline \multicolumn{8}{|l|}{$\begin{array}{l}\text { Children known to have a vision problem: } \\
\text { Referred, prescription given for }\end{array}$} \\
\hline $\begin{array}{l}\text { reading only } \\
\text { Referred, not wearing prescription }\end{array}$ & & & $\begin{array}{l}6 / 5 \\
6 / 12 \\
6 / 60\end{array}$ & $\begin{array}{l}6 / 36 \\
6 / 18 \\
6 / 60\end{array}$ & $\begin{array}{l}6 / 18 \\
6 / 5 \\
6 / 9 \\
6 / 18\end{array}$ & $\begin{array}{l}6 / 18 \\
6 / 24 \\
6 / 18 \\
6 / 18\end{array}$ & $\begin{array}{l}2 \\
5\end{array}$ \\
\hline Referred, not prescribed & $6 / 24$ & $6 / 12$ & $6 / 24$ & $6 / 6$ & & & 2 \\
\hline $\begin{array}{l}\text { Not referred, wearing recent } \\
\text { prescription }\end{array}$ & $6 / 18$ & $6 / 6$ & $\begin{array}{l}6 / 60 \\
6 / 24 \\
6 / 24\end{array}$ & $\begin{array}{l}6 / 6 \\
6 / 6 \\
6 / 18\end{array}$ & $6 / 18$ & $6 / 9$ & 5 \\
\hline $\begin{array}{l}\text { Not referred, will not wear recent } \\
\text { prescription }\end{array}$ & $\begin{array}{l}6 / 12 \\
6 / 5 \\
6 / 9\end{array}$ & $\begin{array}{l}6 / 18 \\
6 / 36 \\
6 / 18\end{array}$ & $\begin{array}{l}6 / 6 \\
6 / 18 \\
6 / 6 \\
6 / 36\end{array}$ & $\begin{array}{l}6 / 24 \\
6 / 12 \\
6 / 18 \\
6 / 36\end{array}$ & $\begin{array}{l}6 / 5 \\
6 / 18 \\
6 / 36 \\
6 / 36 \\
6 / 5 \\
6 / 12 \\
6 / 6\end{array}$ & $\begin{array}{l}6 / 24 \\
6 / 9 \\
6 / 36 \\
6 / 36 \\
6 / 18 \\
6 / 18 \\
6 / 36\end{array}$ & 14 \\
\hline Total & & & & & & & 41 \\
\hline
\end{tabular}

Table 4 Parents' replies to questionnaire about their children's past ocular/vision history; data are number (\%)

\begin{tabular}{|c|c|c|c|}
\hline & Year 8 & Year 9 & Year 10 \\
\hline $\begin{array}{l}\text { No of questionnaires returned } \\
\text { Does child have spectacles? }\end{array}$ & 371 & 377 & 321 \\
\hline Yes & $73(20)$ & $74(20)$ & $63(20)$ \\
\hline No & $275(74)$ & $275(73)$ & $203(63)$ \\
\hline Missing & $23(6)$ & $28(7)$ & $55(17)$ \\
\hline \multicolumn{4}{|c|}{ If no spectacles: } \\
\hline \multicolumn{4}{|c|}{$\begin{array}{l}\text { Has the child had vision checked by } \\
\text { school nurse/optician in the past? }\end{array}$} \\
\hline Yes & $210(76)$ & $200(73)$ & $150(74)$ \\
\hline No & $48(17)$ & $47(17)$ & 31 (15) \\
\hline Don't know & $12(4)$ & $19(7)$ & $12(6)$ \\
\hline Missing & $5(2)$ & $9(3)$ & $10(5)$ \\
\hline \multicolumn{4}{|c|}{ When was child's vision last checked } \\
\hline $1-2$ years ago & $116(55)$ & $88(44)$ & $55(37)$ \\
\hline $3-5$ years ago & $61(29)$ & $72(36)$ & $63(42)$ \\
\hline$>5$ years ago & $23(11)$ & 24 (12) & $28(19)$ \\
\hline Missing/don't know & $10(5)$ & $16(8)$ & $4(3)$ \\
\hline \multicolumn{4}{|c|}{$\begin{array}{l}\text { Has child ever failed a vision check by } \\
\text { school nurse? }\end{array}$} \\
\hline Yes & $22(10)$ & $22(11)$ & $12(8)$ \\
\hline No & $180(86)$ & $171(86)$ & $133(89)$ \\
\hline Missing & $8(4)$ & $7(4)$ & $5(3)$ \\
\hline \multicolumn{4}{|c|}{ After failing check up did child attend } \\
\hline $\begin{array}{l}\text { an optician or school eye } \\
\text { Yes }\end{array}$ & & & \\
\hline $\begin{array}{l}\text { Yes } \\
\text { No }\end{array}$ & $\begin{aligned} 22 \\
0\end{aligned}$ & $\begin{array}{r}19(86) \\
3(14)\end{array}$ & $12(100)$ \\
\hline Missing & 0 & 0 & 0 \\
\hline \multicolumn{4}{|c|}{$\begin{array}{l}\text { Missing } \\
\text { If yes, were spectacles prescribed? }\end{array}$} \\
\hline Yes & $13(59)$ & $12(55)$ & $7(58)$ \\
\hline No & $9(41)$ & $8(36)$ & $5(42)$ \\
\hline Missing & 0 & $2(9)$ & 0 \\
\hline \multirow{2}{*}{\multicolumn{4}{|c|}{ Why doesn't child wear spectacles any }} \\
\hline & & & \\
\hline Don't help & $1(8)$ & $2(17)$ & $1(14)$ \\
\hline Not needed & $12(92)$ & $9(75)$ & $6(86)$ \\
\hline Missing & 0 & $1(8)$ & 0 \\
\hline \multicolumn{4}{|c|}{$\begin{array}{l}\text { If spectacles worn: } \\
\text { At what age (years) did child start to }\end{array}$} \\
\hline \multicolumn{4}{|c|}{$\begin{array}{l}\text { At what age (years) did child start to } \\
\text { wear them? }\end{array}$} \\
\hline $0-3$ & $6(8)$ & $3(4)$ & $3(5)$ \\
\hline $4-6$ & $13(18)$ & $6(8)$ & $7(11)$ \\
\hline $7-9$ & $14(19)$ & $16(22)$ & $9(14)$ \\
\hline $10-12$ & $37(51)$ & $36(49)$ & $18(29)$ \\
\hline $13-15$ & $2(3)$ & $9(12)$ & $22(35)$ \\
\hline Missing & $1(1)$ & $4(5)$ & $4(6)$ \\
\hline \multicolumn{4}{|c|}{$\begin{array}{l}\text { Missing } \\
\text { Who discovered child's vision problem? }\end{array}$} \\
\hline Child/family & 27 (37) & $24(32)$ & $25(40)$ \\
\hline Health visitor/orthoptist & $5(7)$ & $4(5)$ & $3(5)$ \\
\hline School nurse & $1(1)$ & $12(16)$ & $3(5)$ \\
\hline Optician & $27(37)$ & $23(31)$ & $20(32)$ \\
\hline Other & $12(16)$ & $7(9)$ & $8(13)$ \\
\hline Missing & $1(1)$ & $4(5)$ & $4(6)$ \\
\hline
\end{tabular}

of children would have failed screening ( $9 \%$, $7 \%$, and $9 \%$ respectively for years 8,9 , and 10). Although the percentage of children who failed the $6 / 12$ criterion increased with age, the trend was not significant $\left(\chi^{2}=3 \cdot 126\right.$, df 1 , $\left.\mathrm{p}<0 \cdot 10^{10}\right)$.

Only 22 of the 41 children were referred (table 3), because the rest had recently had an eye test and were either wearing $(n=5)$ or refused to wear the recent prescription $(n=14)$. Nine of the 22 referred children were known to have or have had a vision problem in the past and to have had spectacles previously.

Seven of the 22 referred children received a new prescription and wore the spectacles. Six were given a prescription but refused to wear the spectacles. For five children, a prescription was deemed unnecessary or of no benefit, and two were given a prescription for reading only. The remaining two cases were referred to their general practitioners (GPs) by their optometrists. One, a 13 year old boy, had nystagmus that had been diagnosed at the age of 5 years; there was no record of rereferral to the eye hospital and it was presumed that his GP took no further action. The second, a 14 year old girl, had acuities of $6 / 12$ in both eyes that could not be improved by refraction. She was referred to the eye hospital but did not attend. Her GP was informed but did not request a further appointment. Thus less than $1 \%(9 / 1069)$ of the children benefited from vision screening.

Questionnaire responses indicated a discrepancy between the percentage of children wearing spectacles when tested (14\%) and the percentage of parents reporting that their child had spectacles $(20 \%)$ (table 4$)$. The number of children with visual acuity worse than $6 / 12$ and known to have had spectacles in the past $(n=21)$ accounts for only $2 \%$ of this discrepancy. It is assumed that the remainder is made up of children who no longer benefit from or have need for spectacles, and those given spectacles for reading only.

Almost $50 \%$ of children reported as having spectacles were first prescribed spectacles between 10 and 12 years of age, with a steady increase during childhood (see table 4). Data for year 10 children ( 15 year olds) suggest that the rate of spectacle prescription continues to increase after 12 years of age; more year 10 children started to wear spectacles between 13 and 15 years (35\%) than between 10 and 12 years $(29 \%)$.

Parents reported that children's vision problems were detected most frequently by the child or a member of the family (38\%) and this percentage remained fairly constant, irrespective of the age at which the problem was detected. The second most common source was an optometrist $(35 \%)$ during a routine eye examination. School nurses were reported to have detected only about $10 \%$ of problems between 4 and 12 years.

The percentage of problems detected by different sources depended on the age that a problem was discovered (table 5). Optometrists detected few vision problems up to the age of 6 years, but detected $40 \%$ of 
Table 5 Children of all ages (years) who have spectacles, according to parents. Who detected the child's vision problem, according to the age at which the problem was discovered; data are number (\%)

\begin{tabular}{llllllc}
\hline & $0-3$ & $4-6$ & $7-9$ & $10-12$ & $13-15$ & Total \\
\hline Child/family & $5(42)$ & $9(35)$ & $12(31)$ & $35(38)$ & $15(48)$ & $76(38)$ \\
Optician & 0 & $5(19)$ & $14(36)$ & $39(42)$ & $12(39)$ & $70(35)$ \\
Health visitor/orthoptist & $5(42)$ & $5(19)$ & $1(3)$ & $1(1)$ & 0 & $12(6)$ \\
School nurse & 0 & $4(15)$ & $5(13)$ & $7(8)$ & 0 & $16(8)$ \\
Other & $2(16)$ & $3(12)$ & $7(18)$ & $11(12)$ & $4(13)$ & $27(13)$ \\
Total & 12 & 26 & 39 & 93 & 31 & 201 \\
\hline
\end{tabular}

problems in children of 7 years and older. Health visitors or orthoptists were reported to have detected about $40 \%$ of problems up to 3 years of age.

About $75 \%$ of children described as not having spectacles were reported to have had a vision check by a school nurse or optometrist in the past, with about $10 \%$ of these having failed a vision check at some time. Almost all of those who had failed a check had been referred to an optometrist or a school eye clinic and had attended for an eye examination; however, less than $60 \%$ were reported to have been prescribed spectacles.

Table 6 shows that $55 \%$ of year 8 children who did not have spectacles were reported to have had a vision check by a school nurse or optometrist within the last two years. However, this percentage decreased significantly for the older groups, to $44 \%$ for year 9 and $37 \%$ for year $10 \quad\left(\chi^{2}=14 \cdot 08, \mathrm{df}=1\right.$, $\mathrm{p}<0.001)$. About $15 \%$ of children appeared not to have had their vision checked in the last five years.

\section{Discussion}

Using a criterion of worse than $6 / 12$, about $4 \%$ of children failed vision screening. For a criterion of worse than $6 / 9$, this figure increased to about $8 \%$, higher than expected from recent vision screening data. This finding is consistent with the belief that school nurses often use their judgment when deciding whether or not to refer a child for an eye test. Although the proportion of children who failed the $6 / 12$ criterion appeared to increase slightly with age $(p<0 \cdot 10)$, there was no evidence at all of a similar increase for a $6 / 9$ criterion. This failure of the study to show an increase in the number of children failing vision screening needs to be interpreted in the context of the power of the study. Because the actual sample size was smaller than planned (1069 instead of $1500)$ and the observed probability of failing screening lower than originally estimated $(0.04$ instead of 0.07 ), the study had a power of approximately $0 \cdot 85$ for detecting a $4 \%$ increase

Table 6 Children who do not have spectacles, according to parents. Number of years since last vision check by school nurse or optician by age group; data are number (\%)

\begin{tabular}{lcccc}
\hline & Year 8 & Year 9 & Year 10 & Total \\
\hline 1-2 years & $116(55)$ & $88(44)$ & $55(37)$ & $259(44)$ \\
3-5 years & $61(29)$ & $72(36)$ & $63(42)$ & $213(36)$ \\
>5 years & $23(11)$ & $24(12)$ & $28(19)$ & $88(15)$ \\
Don't know & 0 & $2(1)$ & 0 & $2(<1)$ \\
Missing & $10(5)$ & $14(7)$ & $4(3)$ & $28(5)$ \\
Total & 210 & 200 & 150 & 590 \\
\hline
\end{tabular}

in the incidence of failing screening between 13 and 15 year olds. We therefore conclude that the proportion of secondary schoolchildren failing screening increases by less than $2 \%$ per year, implying that the majority of children who are likely to benefit from screening find their own way to an optometrist.

This conclusion is supported by two other findings. Firstly, although there was a steady rise in the proportion of children wearing spectacles with age, less than $1 \%$ benefited from screening and about half of the children who failed screening had recently had an eye test. Secondly, the questionnaire results showed that almost $50 \%$ of children who did not have spectacles had had their vision checked in the last two years, despite having had no school vision screening from about 10 years of age.

The children who failed vision screening but who did not benefit are unlikely to have had a vision problem in the classroom, as only $12 / 41$ children had reduced visual acuity bilaterally. In their teenage years, children are not in danger of damaging their vision by failing to wear a unilateral correction, although a substantial difference in refractive error between the eyes may cause 'eye strain' and/or headaches. Therefore it is perhaps not surprising that many children did not wear spectacles that were prescribed for them. It is also possible that optometrists may not have prescribed small unilateral prescriptions if children stated their unwillingness to wear spectacles at the time of the eye examination; these children are likely to have been described as not benefiting from spectacles. Furthermore, about $2 \%$ of children are likely to have some longstanding reduction of visual acuity resulting from developmental amblyopia, ${ }^{6} 1112$ which cannot be corrected by spectacles. Bilateral amblyopia is extremely rare $^{13}$ and therefore most affected children should not experience vision problems in the classroom. ${ }^{12}$

Twelve children had reduced visual acuity bilaterally. Four were not referred because they had recently had an eye examination; three refused to wear spectacles or did not benefit from refraction and the fourth was a child with special needs who was already wearing spectacles. Five children were prescribed spectacles that improved their visual acuity, but only three wore them. One child was given a prescription for reading only that did not improve distance visual acuity (6/18 in both eyes); this child may have had bilateral amblyopia. The remaining two children were referred to their GPs. Thus only 3/1069 children screened had a significant bilateral visual problem, and benefited from having it detected.

The main criteria for screening are: (a) the condition being screened for is common, (b) it is a significant health problem, (c) it is amenable to treatment at a reasonable cost, and (d) a reliable and cheap screening test exists. ${ }^{212}$ The findings of the current study, that few children benefited from screening, that many would not wear spectacles prescribed for them, and that most children likely to benefit from an eye test find their own way to an optometrist, suggest that vision screening 
in secondary schools is not an effective use of community nursing resources.

There have been dramatic changes in the quality of primary health care services for children as vision screening was instigated (see introduction), and it is perhaps not surprising that a screening initiative established to meet a need in the 1950s is no longer necessary. Nevertheless, our data show that there are still children of secondary school age who have vision health care needs. The finding that vision screening is not an effective way of meeting these needs is no reason to ignore them.

We believe the study provides the evidence to justify redefining the role of school nurses with respect to vision care for children in secondary schools. We propose that this new role should be consultative, with school nurses providing a flexible and focused input where the need arises by offering advice and discussing possible courses of action with children, teachers, and parents. Such a role would be in keeping with current community health care goals for increasing children's awareness of and responsibility for their own health. ${ }^{14}$

As a result of this study, vision screening for secondary children in Oxfordshire has been discontinued. Alternative ways of redefining the school nurse role for this age group are being evaluated. These alternatives focus on:

(1) Providing the opportunity for children to check their own visual acuities.

(2) Encouraging children to wear spectacles if they gain a significant benefit.

(3) The need for children to be made aware of the importance of good vision, for example for driving and certain careers.

(4) Resolving the uncertainty of parents and/or teachers about the need for spectacles when a child claims that he/she gets no benefit from them.

The current study focused on vision screening in secondary schools. However, the replies to the questionnaire suggest that school vision screening at younger ages also identifies few previously unknown eye/vision defects. Consequently, we believe that careful evaluation of the effectiveness of school vision screening at all ages is required, with community nursing departments maintaining a creative and flexible approach to the role of the school nurse.

We are grateful for comments from Dr Aidan Macfarlane during preparation of this paper. The study was funded by a grant from the Oxford Regional Health Authority Locally Organized Research Scheme (grant 91/2).

1 Stewart-Brown SL, Haslum M. Screening of vision in school: could we do better by doing less? BMF 1988; 297 1111-3.

2 Wilson JMG, Jungner G. Principles and practice of screening for disease. Geneva: WHO, 1968. (Public health paper, No 34 .)

3 Tibbenham AD, Peckham CS, Gardiner PA. Vision screening in children tested at 7,11 and 16 years. $B M \mathcal{F}$ 1978; i: 1312-4.

4 Hardman-Lea SJ, Haworth SM. An assessment of the present system for visual screening of school children in Nottingham. British Orthoptic fournal 1989; 46: 20-5.

5 Hall DMB. Health for all children: a programme for child health surveillance. Oxford: Oxford University Press, 1989.

6 Laatikainen L, Erkkila H. Refractive errors and other ocular findings in school children. Acta Ophthalmol (Copenh) 1980; 58: 129-36.

7 Charman WN. Visual standards for driving. Ophthalmic Physiol Opt 1985; 5: 211-20.

8 Tielsch JM, Sommer A, Witt K, Katz J, Royall RM. Blindness and visual impairment in an American urban population: the Baltimore eye survey. Arch Ophthalmo 1990; 108: 286-90.

9 Office of Population Censuses and Surveys. Key population and vital statistics: local and health authority areas. London: HMSO, 1991.

10 Everitt BS. The analysis of contingency tables. London: Chapman Hall, 1977.

11 Von Noorden GK. Binocular vision and ocular motility: theory and management of strabismus. St Louis: CV Mosby, 1985: 211-2.

12 Stewart-Brown S. Visual defects in school children: screening policy and educational implications. In: MacFarlane IA, ed. Progress in child health. Vol 3. Edinburgh: Churchill Livingstone, 1984: 14-37.

13 Fowler MS, Mason AJS, Richardson A, Stein JF. Yellow spectacles to improve vision in children with binocula amblyopia. Lancet 1991; 338: 1109-10.

14 Department of Health. The health of the nation: a consultative document for health in England. London: HMSO, 1991. 